INTERNATIONAL JOURNAL OF MECHANICAL SCIENCES

https://www.journals.elsevier.com/international-journal-of-mechanical-sciences

Impact factor $=\mathbf{4 . 1 3 4}$

Accepted December $12^{\text {th }} 2019$

\title{
NUMERICAL SIMULATION OF THERMAL RADIATION INFLUENCE ON NATURAL CONVECTION IN A TRAPEZOIDAL ENCLOSURE: HEAT FLOW VISUALIZATION THROUGH ENERGY FLUX VECTORS
}

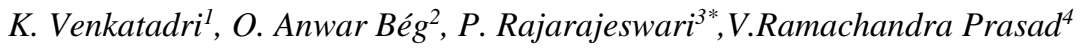 \\ ${ }^{I}$ Department of Mathematics, Sreenivasa Institute of Technology and management studies, Chittoor-517127, India. \\ ${ }^{2}$ Magnetohydrodynamics, Biological Propulsion and Energy Research, Aeronautical and Mechanical Engineering Division, \\ University of Salford, M5 4WT, UK. \\ Department of Computer Science and Engineering, Kingston Engineering College, Vellore-632014, India \\ ${ }^{3}$ Department of Mathematics, School of Advanced Sciences, Vellore Institute of Technology, Vellore - 632014, India.
}

*Corresponding Author: rajacse77@gmail.com

\section{GRAPHICAL ABSTRACT}

Augmentation of heat transfer occurrence describing the complete structure of heat, energy (Energy flux vectors) and fluid flow in a trapezoidal enclosure in presence of the thermal radiation. The computational results are describing the various values of thermal radiation of the trapezoidal enclosure and their effect on heat transfer rate.

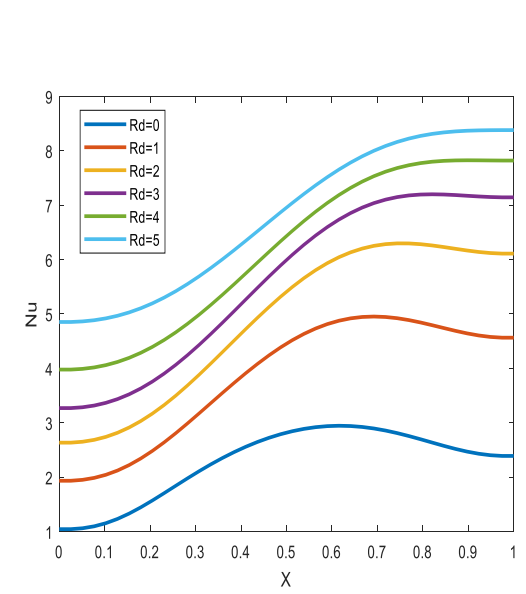

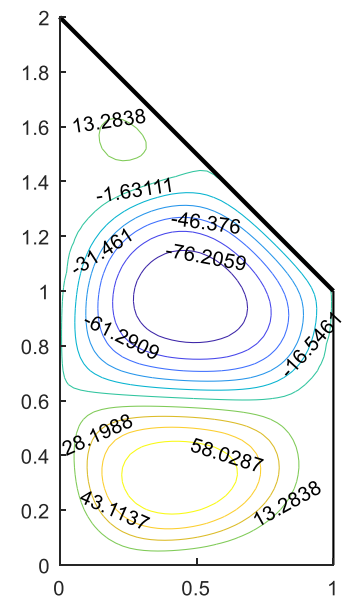

$\psi$

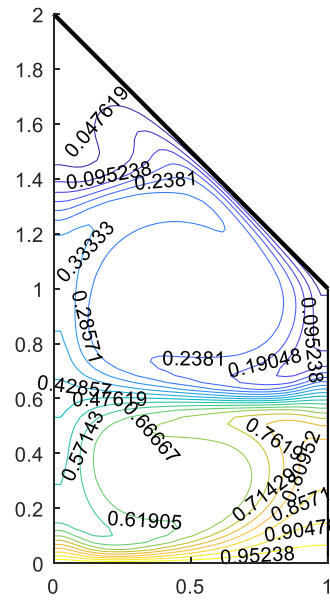

$\theta$

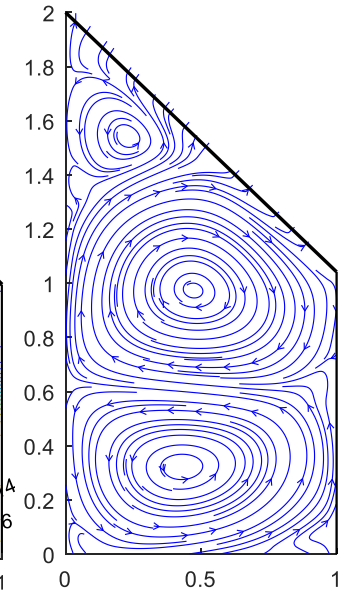

$\bar{E}$

\section{ABSTRACT}

A theoretical and numerical study of natural convection intwo-dimensional laminar incompressible flow in a trapezoidal enclosurein the presence of thermal radiation is conducted, motivated by energy systems applications. Heat flow visualization via the method of energy flux vectors (EFVs) is also included. The trapezoidal cavity has an inclined top wall which in addition 
to the bottom wall is maintained at constant temperature, whereas the remaining (vertical side) walls are adiabatic. The governing partial differential conservation equations are transformed using a vorticity-stream function formulation and non-dimensional variables and the resulting nonlinear boundary value problem is solved using a finite difference method with incremental time steps. EFVs provide abundant details of the heat flow at the core of the enclosure. The larger energy flux vectors indicate high temperature gradient zones and the sparse EFVs correspond to low temperature gradient zone. Heat flow distribution in the trapezoidal enclosure can be clearly elaborated via energy flux vectors and provides a deeper insight into thermal characteristics. A comprehensive parametric study is performed to evaluate the impact of Rayleigh number (buoyancy parameter) and radiation parameter on transport phenomena. The computations indicate that local Nusselt number and velocity are increasing functions of the Rayleigh number and radiation parameter. Significant changes in streamlines, temperature contours and energy streamlines for high Rayleigh number are observed. The energy flux vectors show that a large eddy is formed within the enclosure which migrates towards the cold wall. Greater thermal buoyancy force accelerates the primary flow whereas it decelerates the secondary flow. The simulations are relevant to solar collector systems, enclosure fire dynamics, electronic cooling and fuel cell systems. Furthermore, the computations furnish a good benchmark for more general computational fluid dynamics (CFD) analysis with commercial software e.g. ANSYS FLUENT.

KEYWORDS: Natural convection, Trapezoidal enclosure, Thermal Radiation Parameter, Laminar Two-Dimensional flow, Energy flux vectors (EFVs), solar energy systems.

\section{INTRODUCTION}

One of the major modes in heat transfer is natural (free) convection (buoyancy-driven flow). Free convection in enclosures arises in many diverse engineering applications including cooling of electronics devices, micro-electromechanical system (MEMS), heat exchangers and solar collectors. Convective heat transfer in enclosures can be controlled by applying thermal boundary conditions e.g. with side wall heating or bottom wall heating. Vahl Davis et al. [1] investigated the convection in a differentially heated enclosure containing air (Prandtl number of 0.7). Ostrach [2] conducted an important study of convective flow of air in a square enclosure in the presence of differentially heated side walls. Xin and Le Quéré [3] investigated the turbulent flow in an enclosure with different aspect ratios. Han [4] reported on unsteady thermal convection in a square cavity at large Rayleigh number for the case of differentially heated vertical walls. Minevet al. [5] simulated the convective flow in a cavity with a second order splitting computational scheme. 
Buoyancy-driven convection in square and non-square (e.g. trapezoidal) enclosures has been studied widely in the literature. Many of these investigations have considered the influence of wall thermal boundary conditions and aspect ratios of the enclosures on free convection. Sheikha et al. [6] considered the case where inclined sidewalls are maintained at different temperatures of the trapezoidal enclosure filled with nine different nanofluids using a Tiwari-Das volume fraction model. Umadevi and Nithyadevi [7] studied the natural convection in a silver-water nanofluid filled square enclosure with sinusoidal temperature distribution. Vijaybabu [8] examined the entropy generation in buoyancy-driven flow of copper oxide-water nanofluid in a circular enclosure. MilaniShirvan et al. [9] simulated the radiative natural convection flow in a parabolic solar enclosure.

Natural convection as noted earlier has considerable applications in drying technologies [10], cooling of electronic components [11], lead acid-batteries [12] and thermal storage systems [13]. The temperature distribution in these enclosures is critical to performance. Several researchers studied heat transfer in a square enclosure by computing the isotherms and local and average Nusselt numbers. These analyses have usually considered two cases (Case I: differentially heated enclosures and Case II bottom wall heated enclosures). Fluid flow driven by both buoyancy and the effect of inclination in the presence of discrete heating has been addressed by García et al. [14]. They conducted a numerical study for inclination angles varying from 0 to $90^{\circ}$ and also aspect ratios varying from 0.25 to 1 .In enclosures where bottom wall heating and top wall cooling is imposed, the regime is generally known as Rayleigh-Benard convection. Yashida and Hamano [15] discussed the role of Rayleigh-Benard boundary conditions in enclosure convection. An experimental study was presented by Tso et al.[16]on Rayleigh- Benard convection in a nonsquare enclosure filled with water. Mukul et al. [17] examined Prediction of convective heat transfer in cubical enclosure with the combined effects of thermal radiation and partitions. Biswalet al. [18] studied entropy generation in natural convection with Rayleigh-Benard heating and differentially heating of the enclosure curved walls.

Natural convection within enclosures has also been investigated using the Bejan heat lines approach in recent years. Vinay et al. [19] reported Bejan's heatline and massline visualization of Cross diffusion impact on MHD convection in porous enclosure with multi-forces. Roy et al. [20] examined various moving wall boundary effects on mixed convection in a porous enclosure with the heatline approach. Vinay Kumar et al. [21] employed Bejan's heat and masslines methodology 
to examine magneto-convection porous enclosure. Arani et al. [22] presented a Bejan heatlines and masslines simulation of double-diffusive convective flow of nanofluid in an enclosure. Heat flow visualization through the heatline approach has been studied by many researchers for various geometries; however, application of this method to more complex geometries is difficult. Visualization of convection via energy flux vectors (EVFs) has therefore been introduced by Hooman [23].Marina et al. [24] addressed magnetohydrodynamic natural convection of ferrofluid within a porous trapezoidal enclosure with an opened top surface. Walid et al.[25] described a detailed computational analysis focused on entropy generation in a prismatic greenhouse enclosure with Rayleigh numbers varying from $10^{3}$ to $10^{6}$. Benzenine et al [26] employed a SIMPLE algorithm-based numerical approach to analyze forced convective flow in a rectangular channel with obstacle. A finite difference technique was used by Bondareva et al. [27] to simulate the hydromagnetic convective heat transfer in an open wavy rectangular enclosure of aspect ratio 4 filled with a porous medium. Selimefendigil and Oztop [28] investigated numerically the influence of flexible walls on mixed magneto-convection in a lid-driven enclosure filled with $\mathrm{CuO}$ nanofluid. Rashad et al. [29] studied the effects of thermal radiation and chemical reaction on double diffusive convection in a square cavity filled with a porous medium with various thermal boundary conditions. Al-Mudhafet al. [30] simulated convection in a trapezoidal porous enclosure with cross diffusion effects. Gorla et al. [31] reported in the impact of heat generation/absorption on magnetohydrodynamic natural convective heat transfer in a two-dimensional square porous enclosure. The impact of heat sink and source location and size on magnetohydrodynamic convective flow in an inclined porous square enclosure filled with $\mathrm{Cu}$-water nanofluid was addressed by Rashad et al. [32]. The effect of thermal boundary condition and magnetic field on electrically conducting nanofluid in a porous square enclosure in presence of localized heat source on bottom wall is examined numerically by Mansour et al. [33].

The present numerical study aims to explore the concept of convectiveheat transfer through energy flux vectors in a trapezoidal cavity in the presence of significant thermal radiation. Radiative transfer is relevant to various materials processing operations and also in solar collector technologies. The velocity, temperature and heat flow distributions within the enclosure are obtained via an in house-computational MATLAB code. In addition, the heat transfer rates at the horizontal walls are computed in terms of the Nusselt number. To the authors' knowledge, the 
current study examines for the first time the natural convection within a trapezoidal enclosure under the effects of thermal radiation with heat flow visualization via EFVs.

\section{GEOMETRY DEFINITION AND FUNDAMENTAL EQUATIONS}

\subsection{Problem description}

The physical model is illustrated in Fig. 1. The regime studied comprises incompressible, laminar unsteady two-dimensional buoyancy driven flow in a trapezoidal cavity. The working fluid is air (Prandtl number is 0.7). The domain of interest is a trapezoidal cavity with uniform high temperature distribution $\mathrm{T}_{\mathrm{h}}$ along the horizontal base wall. The parallel side walls are insulated the no slip velocity condition is imposed. The inclined wall is maintained at temperature $T_{\mathrm{c}}$. The thermal radiation flux is included in the energy conservation equation.

\subsection{Governingequations}

As noted above, unsteady two-dimensional viscous laminar thermal convection in the enclosure is considered. The linear Boussinesq approximation is considered i.e. density variation of the fluid is only simulated via the buoyancy force term. The fluid flow is considered as a laminar and incompressible. In addition, the temperature of the fluid is assumed to be uniform (Local thermal equilibrium (LTE)).Viscous dissipation effects are neglected. Radiative flux is modelled via the Rosseland diffusion approximation:

$\mathbf{q}=\left(q_{r x}, q_{r y}, 0\right), q_{r x}=-\frac{4 \sigma}{3 \beta} \frac{\partial T^{4}}{\partial x}, q_{r y}=-\frac{4 \sigma}{3 \beta} \frac{\partial T^{4}}{\partial y}$

By the help of Taylor series, we expand $\mathrm{T}^{4}$ in terms of the low inclined wall temperature $\mathrm{T}_{\mathrm{c}}$ and ignore higher order terms, leading to:

$T^{4} \approx 4 T T_{c}^{3}-3 T_{c}^{4}$

By the help of the above the radiative flux components are reduced to:

$q_{r x}=-\frac{4 \sigma T_{c}^{3}}{3 \beta} \frac{\partial T}{\partial x}, q_{r y}=-\frac{4 \sigma T_{c}^{3}}{3 \beta} \frac{\partial T}{\partial y}$

Under the above approximations, the appropriate non-dimensional governing equations (mass, momentum and energy conservation) may be shown to take the form [13]: 
$\nabla \cdot \mathbf{v}=0$

$\operatorname{Pr} \nabla^{2} \mathbf{v}--\nabla p=(\mathbf{v} \cdot \nabla) \mathbf{v}-\operatorname{Ra} \operatorname{Pr} \theta \overline{e_{y}}+\mathbf{v}_{\tau}$

$\frac{\partial \theta}{\partial \tau}+\mathbf{v} \cdot(\nabla \theta)=\left(1+\frac{4 R d}{3}\right) \nabla^{2} \theta$

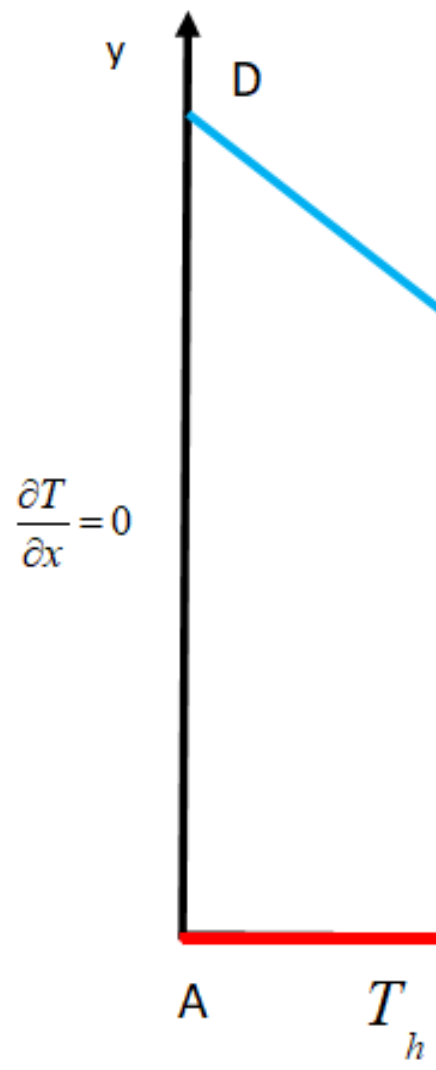

a

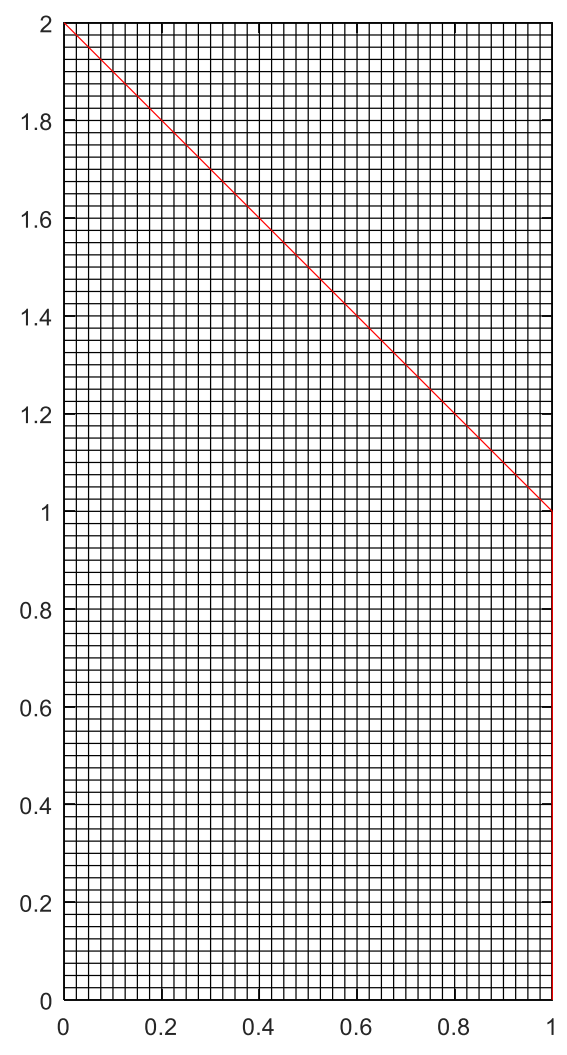

b

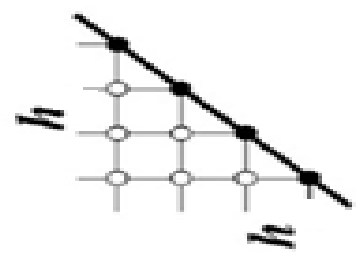

Fig.1 Geometry, utilized mesh and the boundary conditions

To simplify the equations, it is judicious to introduce the following dimensionless parameters: 


$$
\begin{aligned}
& \tau=\frac{t u_{0}}{L}, \quad X=\frac{x}{L}, \quad Y=\frac{y}{L}, \quad U_{x}=\frac{u}{u_{0}}, \quad U_{y}=\frac{v}{u_{0}}, \quad \theta=\frac{T-T_{c}}{T_{h}-T_{c}}, \quad P=\frac{p}{u_{0}^{2} \rho_{f}}, \\
& u_{0}=\frac{\alpha}{L}
\end{aligned}
$$

Here $\tau$ is dimensionless time, $X$ and $Y$ are dimensionless spatial coordinates, $U_{x}$ and $U_{y}$ are dimensionless velocity components, $\theta$ is the dimensionless temperature, $P$ is the dimensionless pressure, $u_{0}$ is an arbitrary velocity, and $T_{h}$ and $T_{c}$ are the temperature of the vertical walls. In Eqn. (5), $R a$ and $\operatorname{Pr}$ are Rayleigh and Prandtl numbers respectively and are defined as:

$$
R a=\frac{g \beta\left(T_{h}-T_{c}\right)\left(1-C_{c}\right) L^{3}}{v_{f}^{2}}, \operatorname{Pr}=\frac{v_{f}}{\alpha_{f}} \text { and } R d=-\frac{4 \sigma T_{c}^{3}}{k \beta}
$$

\subsection{Vorticity Stream Function Formulation}

Stream function $\psi$ and vorticity $\omega$ are defined in dimensional form as:

$$
\begin{aligned}
& U_{x}=\frac{\partial \psi}{\partial Y}, U_{y}=-\frac{\partial \psi}{\partial X} \\
& \omega=\frac{\partial U_{y}}{\partial X}-\frac{\partial U_{x}}{\partial Y}=-\nabla^{2} \psi
\end{aligned}
$$

With the aid of the above equations, the governing momentum equation can be written in vorticity form as follows.

$$
\frac{\partial \omega}{\partial \tau}-\operatorname{Pr} \nabla \cdot(\nabla \omega)=-\frac{\partial \psi}{\partial Y} \frac{\partial \omega}{\partial X}+\frac{\partial \psi}{\partial X} \frac{\partial \omega}{\partial Y}+R a \cdot \operatorname{Pr} \frac{\partial \theta}{\partial X}
$$

The appropriate boundary conditions for the present study are prescribed as follows:

$$
\begin{aligned}
& \theta=0 \text { on the upper slanted wall (CD) } \\
& \theta=1 \text { on the bottom wall (AB) } \\
& \frac{\partial \theta}{\partial n}=0 \text { on the other walls (BC\& AD) }
\end{aligned}
$$

The vorticity on the boundary of the trapezoidal enclosure is calculated from the stream function formulation. The local and average (mean) heat transfer rates are defined respectively as follows (where $R d$ is the radiative parameter): 


$$
N u=-\left(1+\frac{4 R d}{3}\right)\left(\frac{\partial \theta}{\partial X}\right)_{X=0} \text { and } N u_{M}=-\int_{0}^{1}\left(\frac{\partial \theta}{\partial X}\right) d Y
$$

\subsection{Energy flux vector (EFV)}

The energy flux vector (EFV) method [23] is an excellent tool for visualization of heat flow in a trapezoidal enclosure. The $\mathrm{EFV}(\bar{E})$ is defined as follows:

$$
\bar{E}=\left(U_{x} \theta-\left(1+\frac{4 R d}{3}\right) \frac{\partial \theta}{\partial X}\right) e_{X}+\left(U_{y} \theta-\left(1+\frac{4 R d}{3}\right) \frac{\partial \theta}{\partial Y}\right) e_{Y}
$$

The energy flux vectors $(\bar{E})$ are evaluated via post processing. The tangent to the heatlines is generally defined as energy flux vectors [23].

\section{SOLUTION METHOD AND VALIDATION}

The dimensionless coupled nonlinear governing Eqns. (11) and (6) together with the corresponding thermal and stream function boundary conditions are solved numerically. The primitive variable formulation helps to eliminate pressure term in the momentum equation. The development of house-computational MATLAB code is easier than the pressure-velocity algorithms. The coupled governing nonlinear equations are solved via a finite difference method (FDM). The details of this method are well described by Venkatadri et al.[34].This technique is very efficient for computing viscous fluid dynamics problems and a good alternative to other methods such as finite element, control volume finite element etc. The finite difference method with primitive variable formulation helps us to increase the accuracy level, the details of this finite difference technique and accuracy results are documented in [35-40]. To validate the present in house-computational MATLAB code, benchmarking with earlier numerical [41-43] studies of convective flow in a differentially heated enclosure filled with air are considered. Table.1. shows the average Nusselt number along the hot wall for a wide range of Rayleigh numbers $\left(\mathrm{Ra}=10^{3}-10^{6}\right)$. Evidently very good correlation with the developed in house-computational MATLAB code is obtained. Confidence in the present simulations is therefore justifiably high.

\section{RESULTS AND DISCUSSION}

Analysis of energy flux vectors for natural convection within a trapezoidal enclosure is conducted. The influence of Rayleigh number $\left(\mathrm{Ra}=10^{3}-10^{6}\right)$ and thermal radiation $(\mathrm{Rd}=1-5)$ on natural convective heat transfer is studied with $\operatorname{Pr}=0.7$. The obtained results are depicted in the form of streamlines, isotherms, energy flux vector and local and average Nusselt number for wide range values of $R a$ and $R d$. 
Figure.2 illustrates the numerical results for flow patterns (streamlines), temperature contours and energy flux vectors for $R d=1$ and $R a=10^{3}$. The domain of interest considered is uniform heating of the horizontal walls of the enclosure, where the temperature distribution along the bottom wall is uniform and the temperature of the inclined top wall is 0 . A single enlarged convective cell is developed near the inclined cold top wall and the circulation occupying the whole enclosure is approximately $65 \%$. The isotherms are distributed throughout the entire enclosure, while the temperature contours are parallel near the bottom wall. However, the nature of the isotherms computed is modified as we progress towards the cold wall. This is due to thermal conduction heat transfer. The EFV's are also computed and these visualize the heat transfer. The energy flux vector expresses the direction of the heat flow from the hot surface to the cold surface.

The streamlines, temperature contour and Energy flux vector for $\mathrm{Ra}=10^{4}$ and $\mathrm{Rd}=1$ are presented in Figure.3. A strong convective single enlarged eddy is formed within the enclosure, and this is attributable to a shift in thermal conduction to thermal convection. By the enhancement of fluid motion with rising of buoyancy force, the isotherms are stretched towards the cold wall. The strength of temperature contours is increased with increasing thermal Rayleigh number. The parallel isotherms are transformed to more inclined isotherms; more inclined lines are noticed in the middle of the enclosure and a corner of the left portion of a bottom wall. This behavior is induced due to temperature variations; the temperature of left portion of the bottom wall is high compared to other zones in the enclosure. The energy flux vectors follow the flow direction, as observed clearly in the Fig.3.

Figure.4illustrates the steady-state contours for streamlines, temperature, and energy flux vectors for $\mathrm{Ra}=10^{5}$ and $\mathrm{Rd}=1$. The velocity of the fluid particles gradually increases when $\mathrm{Ra}=10^{5}$, due to stronger buoyancy force relative to viscous force in the regime. The fluid rises along the left vertical wall and descends towards the cold inclined wall; this mechanism generates a strong convective cell in the middle of the enclosure and a minor cell is formed whereas low temperature is computed. The heat transport within the cavity is illustrated by energy flux vectors. Heat transfer primarily occurs from the hot wall towards the cold inclined wall. In this process, high temperature is observed in the middle of the enclosure and low temperature is noticed in the vicinity of the minor eddy. The energy flux vectors show that a large eddy is formed within the enclosure which migrates towards the cold wall and behaves similar to the streamline patterns.

The impact of Rayleigh number $\mathrm{Ra}=10^{6}$ on convective flow patterns (streamlines), isotherms and flux vector of energy are shown in Figure.5 for $R d=1$. Significant changes in streamlines, temperature contours and energy streamlines for high Rayleigh number are observed. At $\mathrm{Ra}=10^{6}$, a drastic enhancement of fluid motions is generated, and this produces more than one circulation zone within the trapezoidal enclosure. The minor circulation appears in the top portion of the enclosure and two clockwise and anti-clockwise eddies are synthesized in the middle of the enclosure. The anticlockwise convective circulation is formed along the hot wall and the clockwise convective circulation is formed near the cold wall besides the minor cell developed above the major convective cells. Three different thermal zones (plumes) are developed due to 
formation of convective cells. A major thermal layer is formed along the hot wall and another thermal boundary layer is formed along the inclined cold wall. At the high Rayleigh number, the corresponding isotherm contours whirl from the bottom to the top. The thermal plume is developed between the two convective cells. The heat flow analysis via energy flux vectors reveals the heat flow direction from high temperature to low temperature. The heat flow is primarily from the anticlockwise convective cell to the clockwise convective cell and then reaches the cold inclined wall.

The role of the radiative parameter $\mathrm{Rd}$ and thermal Rayleigh number $\mathrm{Ra}$ on fluid flow velocity profiles and local Nusselt number along the bottom wall is illustrated in Figures.6-10. At $\mathrm{Ra}=10^{4}$, the influence of thermal radiation parameter $\mathrm{Rd}$ on velocity profiles $\mathrm{U}$ and $\mathrm{V}$ are shown in Figure. 6. When increasing of radiation parameter $\mathrm{Rd}$ from 1 to 5 both the velocity profiles are enhanced considerably i.e. greater radiative heat flux accelerates the flow in the enclosure. A gradual augmentation of local Nusselt number is observed with enhancement of Rd, as shown clearly from Figure.7, indicating that greater heat transfer is achieved from the wall to the enclosure fluid with higher radiative flux and lower heat transfer is achieved from the wall at $\mathrm{Rd}=0$ (vanishing radiative flux).The influence of Rayleigh number $\mathrm{Ra}$ on velocity profiles $\mathrm{U}$ and $\mathrm{V}$ in addition on local Nusselt number along a bottom wall is exhibited the figures.8-10. Substantial elevation in primary velocity, $U$ (Fig. 8) is achieved with an increase in Rayleigh number Ra from $10^{3}$ to $10^{6}$. The opposite response (Fig. 9) is computed for the secondary velocity $V$. Greater thermal buoyancy force therefore accelerates the primary flow whereas it decelerates the secondary flow. Significant enhancement in local Nusselt number is induced with increasing Rayleigh number, as plotted in Fig. 10. There is also a dramatic morphing in the profiles which evolve from a linear distribution to strongly parabolic profiles with greater buoyancy effect (Higher Rayleigh number).

\section{CONCLUSIONS}

The natural convective flow and radiation heat transfer in an air-filled trapezoidal enclosure is examined numerically. The enclosure base wall is prescribed a uniform high temperature and the top inclined wall is sustained at constant low temperature, while the side walls are thermally insulated. The governing dimensionless conservation equations are solved in vorticity form using a finite difference method. Heat flow analysis is also conducted within the trapezoidal enclosure using Hooman's method. The computations have shown that a very low rate of heat transfer and flow rate are obtained for low Rayleigh number $\left(\mathrm{Ra}=10^{3}\right)$. However multiple circulations and multiple cores of energy flux vectors are found at higher Rayleigh number, $\mathrm{Ra}=10^{6}$. The local Nusselt number and velocities are increasing functions of the Rayleigh number Ra and radiation parameter $\mathrm{Rd}$. It is also noteworthy that thermal radiative flux and buoyancy (as simulated via $\mathrm{Rd}$ and $\mathrm{Ra}$ ) are very good control parameters for heat and fluid flow inside trapezoidal cavities and careful selection of these parameters can achieve optimal heat transfer rates. The present simulations have demonstrated very good accuracy of the finite difference code employed. Future studies may consider nanofluids and non-Newtonian working fluids.

\section{ACKNOWLEDGEMENTS}


The authors are grateful to the reviewers for their comments which have served to improve the article.

\section{NOMENCLATURE}

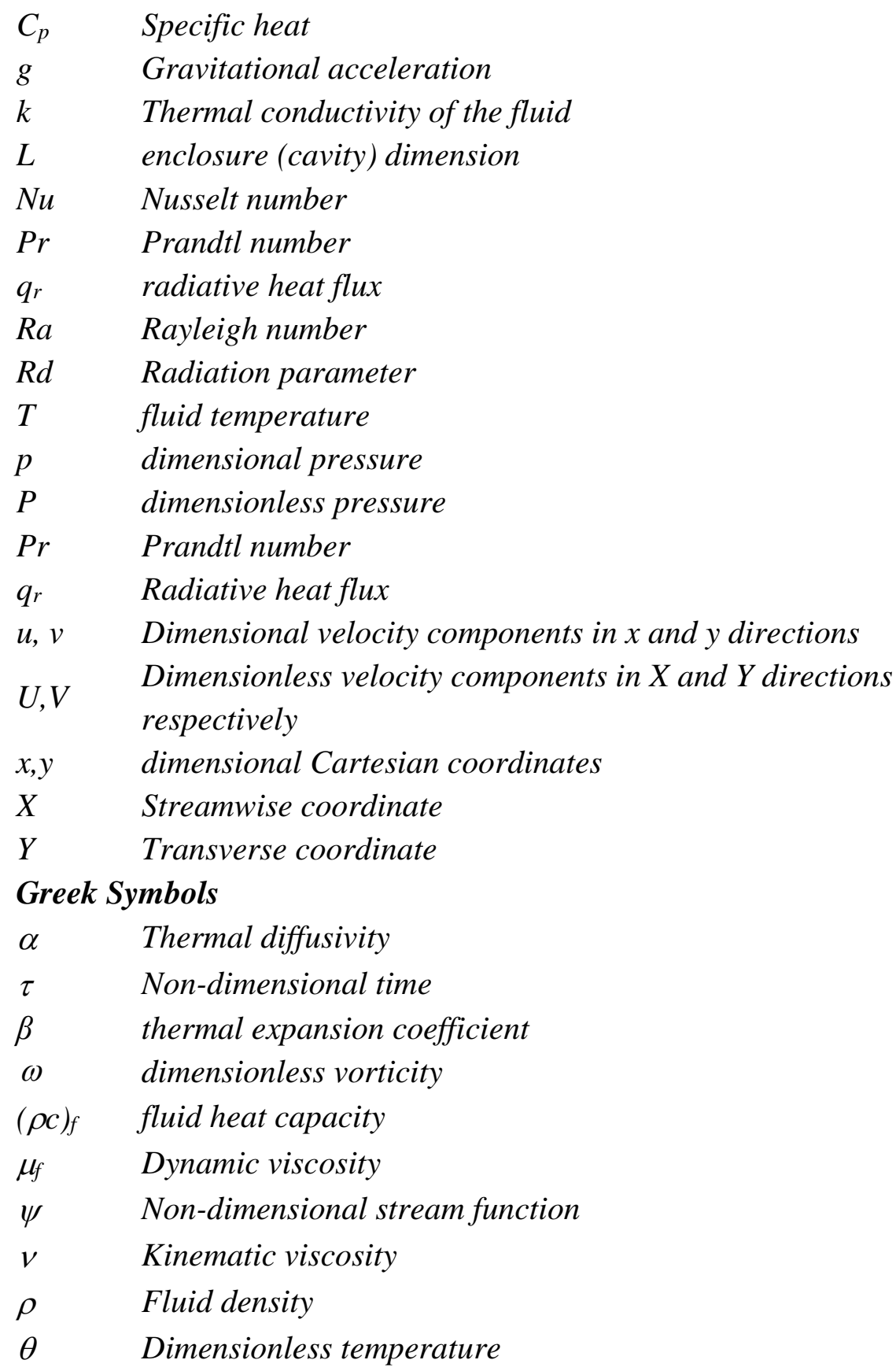




\begin{tabular}{ll}
\multicolumn{2}{l}{ Subscripts } \\
$f$ & Fluid \\
$h$ & Hot \\
$c$ & cold
\end{tabular}

\section{REFERENCES}

[1] Vahl Davis de, G. Natural convection of air in a square cavity: a benchmark numerical solution, International Journal Numerical Methods Fluids 1983; 3: 249-264.

[2] Ostrach S. Natural convection in enclosures, Advances in Heat Transfer, Hartnett, J.P. and Irvine, T.F., Jr 1972; 8:161-227.

[3] Xin S., Le Quéré P. Numerical simulations of 2D turbulent natural convection in differentially heated cavities of aspect ratios 1 and 4. In: Voke P.R., Kleiser L., Chollet JP. (eds) Direct and Large-Eddy Simulation I. Fluid Mechanics and Its Applications, 1994; 26. Springer, Dordrecht.

[4] Han S.M. A transient numerical analysis of high Rayleigh number convection in a differentially heated square cavity, ASME Paper 1984; 84-HT-57.

[5] Minev P., Van de Vosse, Timmermans L. and Van Steenhoven, A. A second order splitting algorithm for thermally-driven flow problems. International Journal of Numerical Methods for Heat \& Fluid Flow 1996; 6 (2): 51-60.

[6] Sheikha M. Al-Weheibi, M.M. Rahman, M.S.Alam, K. Vajravelu. Numerical simulation of natural convection heat transfer in a trapezoidal enclosure filled with nanoparticles. International Journal of Mechanical Sciences 2017; 131-132: 599-612.

[7] Umadevi P, Nithyadevi N. Convection in a sinusoidally heated square enclosure utilizing Ag-water nanofluid with heat generating solid body. International Journal of Mechanical Sciences 2017; 131-132: 712-721.

[8] Vijaybabu T.R. Influence of permeable circular body and $\mathrm{CuO}-\mathrm{H} 2 \mathrm{O}$ nanofluid on buoyancy-driven flow and entropy generation. International Journal of Mechanical Sciences, 2019; 166: 105240. 
[9] MilaniShirvan K., Mamourian M., Mirzakhanlari S., Rahimi A.B., and Ellahi R. Numerical study of surface radiation and combined natural convection heat transfer in a solar cavity receiver. International Journal of Numerical Methods for Heat and Fluid Flow2017; 27 (10): 2385-2399.

[10] Bondareva N.S., Sheremet M.A., Öztop H.F. and Abu-Hamdeh, N. Transient natural convection in a partially open trapezoidal cavity filled with a water-based nanofluid under the effects of Brownian diffusion and thermophoresis. International Journal of Numerical Methods for Heat and Fluid Flow 2018; 28(3): 606-623.

[11] Fetecau C., Akhtar S., Pop I. and Fetecau C. Unsteady general solution for MHD natural convection flow with radiative effects, heat source and shear stress on the boundary. International Journal of Numerical Methods for Heat and Fluid Flow 2017; 27(6): 12661281.

[12] Salari M., Rashidi M.M., HasaniMalekshah, E. and HasaniMalekshah, M. Numerical analysis of turbulent/transitional natural convection in trapezoidal enclosures, International Journal of Numerical Methods for Heat and Fluid Flow 2017; 27(12): 2902-2923.

[13] Sheremet M.A. and Pop, I. Natural convection combined with thermal radiation in a square cavity filled with a viscoelastic fluid, International Journal of Numerical Methods for Heat and Fluid Flow 2018; 28: 624-640.

[14] García F, Treviño C, Lizardi J, Martínez-Suástegui L. Numerical study of buoyancy and inclination effects on transient mixed convection in a channel with two facing cavities with discrete heating. International Journal of Mechanical Sciences 2019; 155: 295-314.

[15] Yoshida M, Hamano Y. Numerical studies on the dynamics of two-layer Rayleigh-Benard convection with an infinite Prandtl number and large viscosity contrasts. Phy. Fluids 2006; 28: 116601 .

[16] Tso C.P, Jin L.F, Tou S.K.W, Zhang X.F. Flow pattern evolution in natural convection cooling from an array of discrete heat sources in a rectangular enclosure at various orientations. Int. J. Heat and Mass Transfer 2004; 47: 4061-4073.

[17] Mukul Parmananda, Amaresh Dalal, Ganesh Natarajan. The influence of partitions on predicting heat transfer due to the combined effects of convection and thermal radiation in cubical enclosures. International Journal of Heat and Mass Transfer 2018; 121: 1179-1200. 
[18] Pratibha Biswal, Basak Tanmay. Role of differential vs Rayleigh-Benard heating at curved walls for efficient processing via entropy generation approach, International Journal of Heat and Mass Transfer, 2018; 124: 390-413.

[19] Vinay Kumar, Krishna Murthy S.V.S.S.N.V.G, Rathish Kumar B.V. Bejan'sheatline and massline visualization of multi-force effect on convection in a porous enclosure. International Journal of Mechanical Sciences 2018; 146-147: 249-271.

[20] Roy M, Roy S, Basak T. Finite element simulations on heatline trajectories for mixed convection in porous square enclosures: Effects of various moving walls. European Journal of Mechanics B/Fluids 2016; 59: 140-160.

[21] Vinay Kumar, Krishna Murthy S.V.S.S.N.V.G, Rathish Kumar B.V. Influence of MHD forces on Bejan's heatlines and masslines in a doubly stratified fluid saturated Darcy porous enclosure in the presence of Soret and Dufour effects - A numerical study. International Journal of Heat and Mass Transfer 2018; 117: 1041-1062.

[22] Ali Akbar Abbasian Arani, Ahmad Ababaei, Ghanbar Ali Sheikhzadeh, Alireza Aghaei. Numerical simulation of double-diffusive mixed convection in an enclosure filled with nanofluid using Bejan's heatlines and masslines. Alexandria Engineering Journal 2018; 57: 1287-1300.

[23] Hooman K. Energy flux vectors as a new tool for convection visualization. Int. J. Numer. Methods Heat Fluid Flow 2010; 20: 240-249.

[24] Astanina Marina S, Sheremet Mikhail A, OztopHakan F, Abu-HamdehNidal. MHD natural convection and entropy generation of ferrofluid in an open trapezoidal cavity partially filled with a porous medium. International journal of Mechanical Sciences 2018; 136: 493-502.

[25] Aich Walid, Kolsi Lioua, Borjini Mohamed N, A. A. A. Al-Rashed Abdullah, Aissia Habib Ben, Oztop Hakan F, Abu-Hamdeh Nidal. Three-dimensional computational fluid dynamics analysis of buoyancy-driven natural ventilation and entropy generation in a prismatic greenhouse. Thermal Science Part: A, 2018; 22(1): 73-85.

[26] Benzenine Hamidou, Saim Rachid, Abboudi Said, Imine Omar, Oztop Hakan F \& AbuHamdeh Nidal. Numerical study of a three-dimensional forced laminar flow in a channel equipped with a perforated baffle. Numerical Heat Transfer Part A-Applications, 2018; 73(12): 881-894. 
[27] Bondareva Nadezhda S, Sheremet Mikhail A, Öztop Hakan F, Abu-Hamdeh Nidal. Heatline visualization of MHD natural convection in an inclined wavy open porous cavity filled with a nanofluid with a local heater. International Journal of Heat and Mass Transfer 2016; 99: 872-881.

[28] Selimefendigil Fatih, Öztop Hakan F. Analysis of MHD mixed convection in a flexible walled and nanofluids filled lid-driven cavity with volumetric heat generation. International Journal of Mechanical Sciences 2016; 118:113-124.

[29] Rashad A., Elsayed Ahmed, S. and Ahmed Mansour, M. Effects of chemical reaction and thermal radiation on unsteady double diffusive convection. International Journal of Numerical Methods for Heat \& Fluid Flow 2014; 24( 5): 1124-1140.

[30] Al-Mudhaf Ali F, Rashad A.M, Ahmed Sameh E, Chamkha Ali. J, EL-Kabeir S.M.M. Soret and Dufour Effects on Unsteady Double Diffusive Natural Convection in Porous Trapezoidal Enclosures. International Journal of Mechanical Sciences 2018; 140: 172-178.

[31] Rama Subba Reddy Gorla, Sadia Siddiqa, Mansour M. A, Rashad A M, Salah T. Heat Source/Sink Effects On Natural Convection Of A Hybrid Nanofluid-Filled Porous Cavity. Journal of Thermophysics and Heat Transfer 2017; 31(4): 847-857.

[32] Rashad A M, Armaghani T, Chamkha Ali. J, Mansour M.A, Entropy Generation and MHD Natural Convection of a Nanofluid in an Inclined Square Porous Cavity: Effects of a Heat Sink and Source Size and Location, Chinese Journal of Physics, 56(1) (2018) 193-211.

[33] Mansour M.A, Ahmed S.E,Rashad A M. MHD Natural Convection in a Square Enclosure Using Nanofluid with the Influence of Thermal Boundary Conditions. Journal of Applied Fluid Mechanics 2016; 9(5): 2515-2525.

[34] Venkatadri K, Abdul Gaffar S, Suryanarayana Reddy M, Ramachandra Prasad V, Hidayathulla Khan B. Md., and Anwar Bég O. Melting heat transfer analysis on magnetohydrodynamic buoyancy convection in an enclosure: a numerical study. Journal of Applied and Computational Mechanics 2020; 6(1): 52-62.

[35] Ertuk E, Corke TC and Gokcol C. Numerical solution of 2-D steady incompressible driven cavity flow at high Reynolds number. International Journal of Numerical Methods in Fluids 2005; 48: 747-774.

[36] Ertuk E and Gokcol O. Fine grid numerical solution of triangular cavity flow. The European Physical Journal - Applied Physics 2007; 38: 97-105. 
[37] Ertuk E and Dursun B. Numerical solutions of 2-D steady incompressible flow in a driven skewed cavity. ZAMM-Journal of Applied Mathematics and Mechanics 2007; 87: 377-392.

[38] Sheremet, M.A. and Pop, I. Natural convection in a square porous cavity with sinusoidal temperature distributions on both side walls filled with a nanofluid: Buongiorno's mathematical model. Transport in Porous Media 2014; 105(2): 411-429.

[39] Sheremet M.A. and Pop, I. Natural convection in a wavy porous cavity with sinusoidal temperature distributions on both side walls filled with a nanofluid: Buongiorno's mathematical model. J. Heat Transfer 2015; 137(7): 072601.

[40] Sheremet Mikhail A, Grosan, T. and Pop, I. Natural convection in a triangular cavity filled with a micropolar fluid. International Journal of Numerical Methods for Heat and Fluid Flow 2017; 27( 2): 504-515.

[41] Manzari M. T. An explicit finite element algorithm for convective heat transfer problems. International Journal of Numerical Methods for Heat and Fluid Flow 1999; 9: 860-877.

[42] Wan D. C, Patnaik B. S. V, and Wei G. W.A new benchmark quality solution for the buoyancy-driven cavity by discrete singular convolution. Numerical Heat Transfer, Part B 2001; 40: 199-228. 


\section{TABLES AND FIGURES}

Table. 1. Comparison of Average Nusselt number $(\mathrm{Nu})$ with $\operatorname{Pr}=0.71$

\begin{tabular}{cccccc}
\hline & & Ref. [1] & Ref. [41] & Ref. [42] & \\
$\mathrm{Ra}$ & $\mathrm{Nu}$ & & & FEM & Present study \\
\hline $10^{3}$ & Average & 1.12 & 1.074 & 1.117 & 1.1185 \\
$10^{4}$ & Average & 2.243 & 2.084 & 2.254 & 2.2526 \\
$10^{5}$ & Average & 4.52 & 4.3 & 4.598 & 4.5907 \\
$10^{6}$ & Average & 8.8 & 8.743 & 8.976 & 8.9905 \\
\hline
\end{tabular}
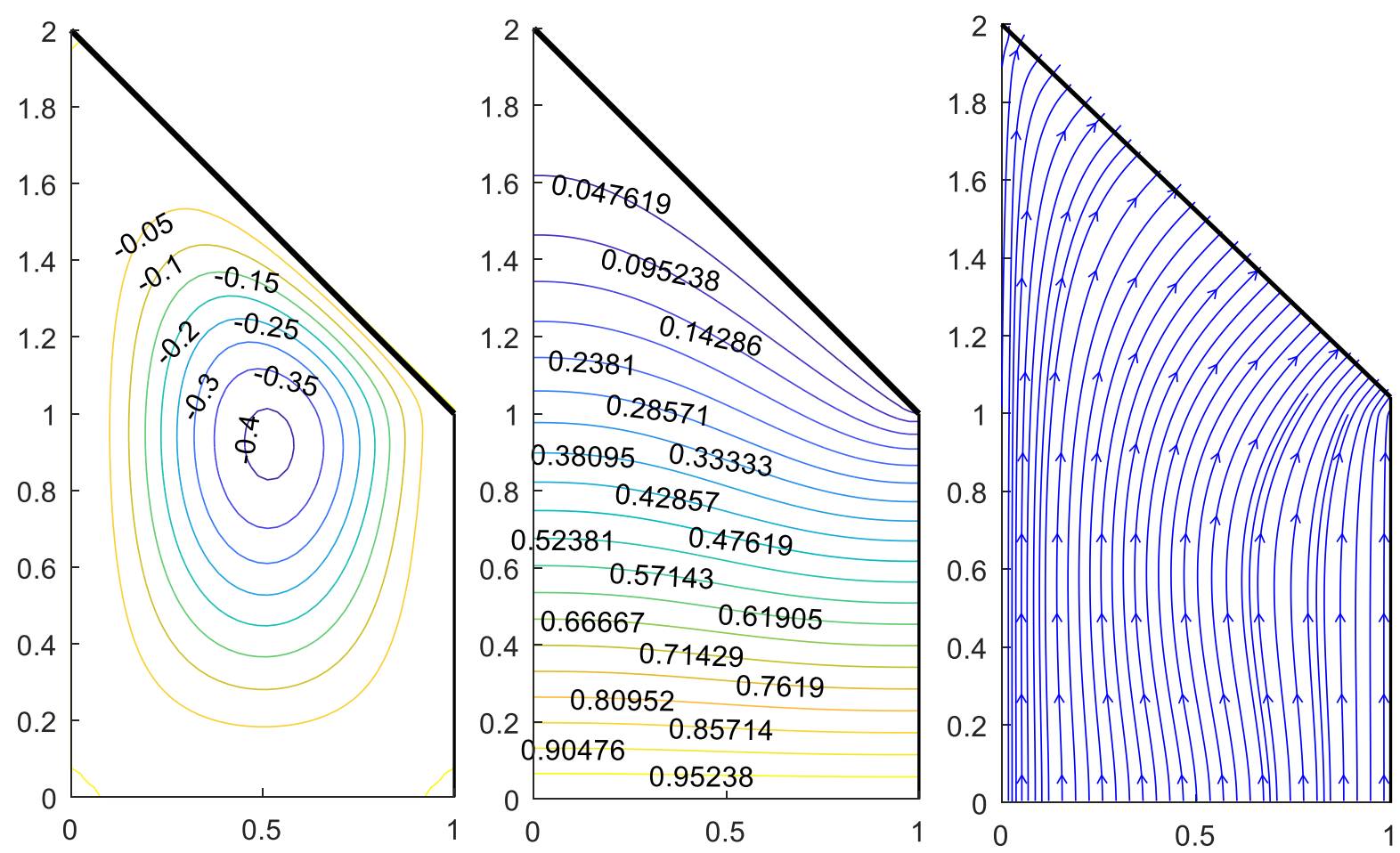

Fig. 2. Streamlines $(\psi)$, Isotherms $(\theta)$ and Energy flux Vector $(\bar{E})$ for $\operatorname{Ra}=10^{3}, \operatorname{Rd}=1, \operatorname{Pr}=0.7$ 

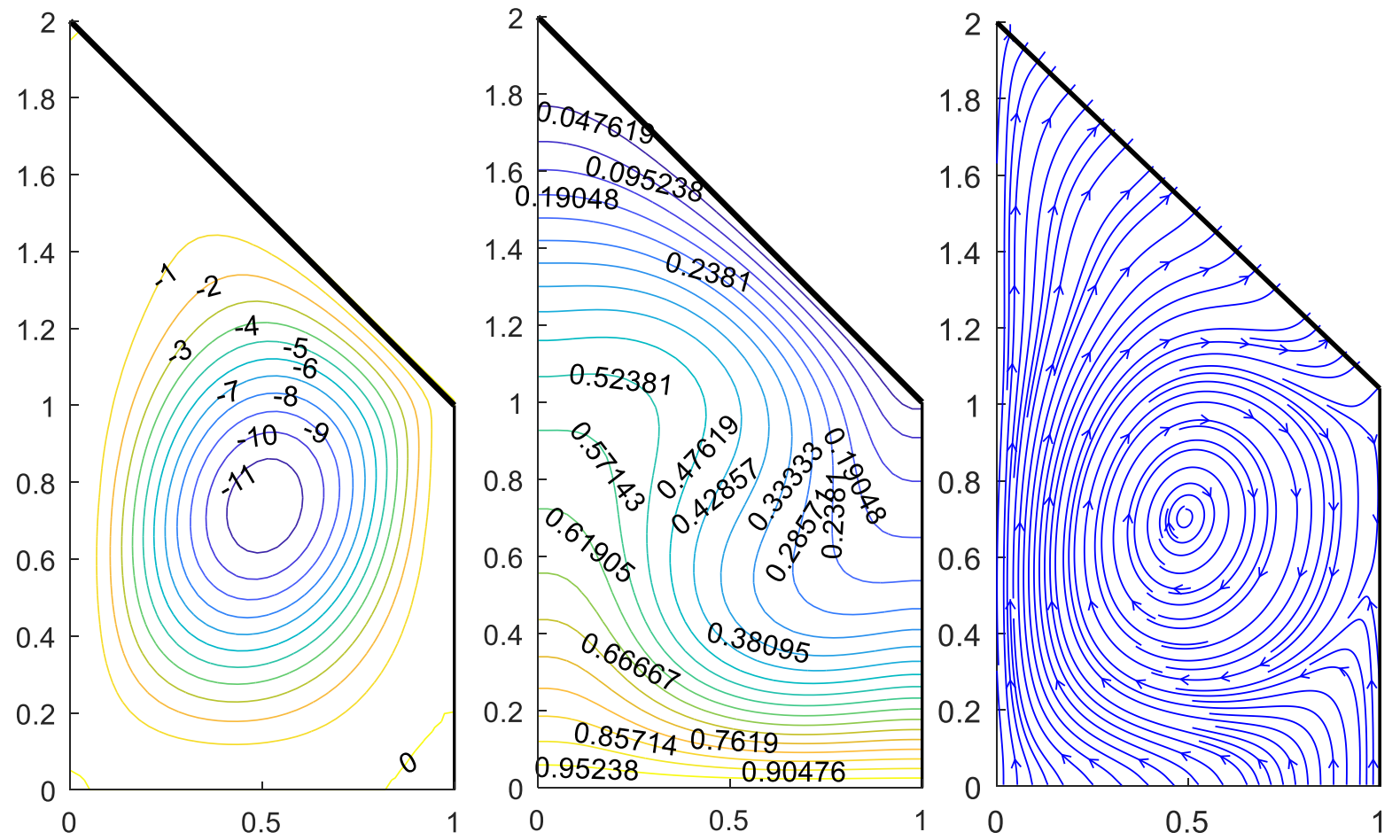

Fig. 3. Streamlines $(\psi)$, Isotherms $(\theta)$ and Energy flux Vector $(\bar{E})$ for $\operatorname{Ra}=10^{4}, \operatorname{Rd}=1, \operatorname{Pr}=0.7$
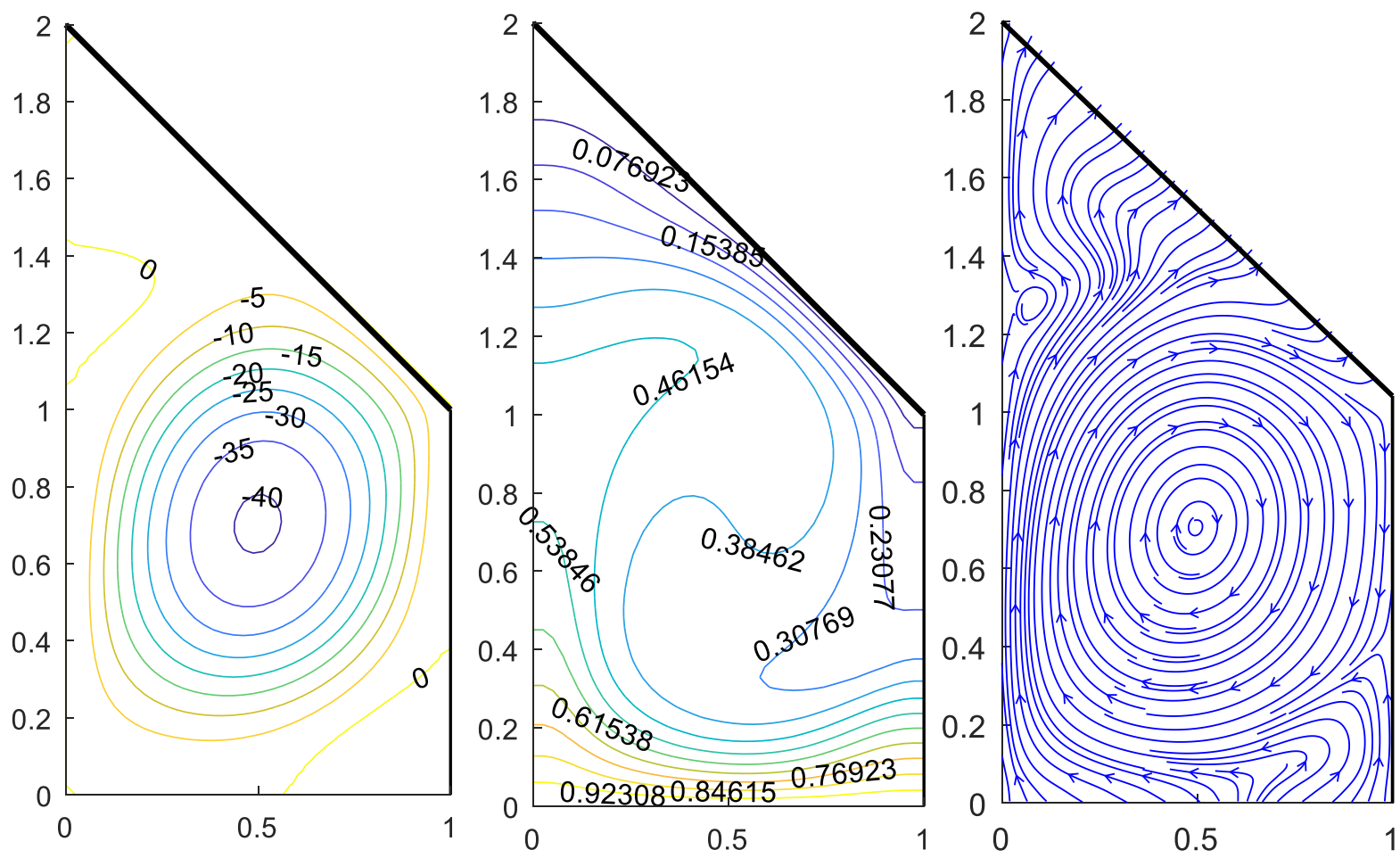

Fig. 4. Streamlines $(\psi)$, Isotherms $(\theta)$ and Energy flux Vector $(\bar{E})$ for $\operatorname{Ra}=10^{5}, \operatorname{Rd}=1, \operatorname{Pr}=0.7$ 

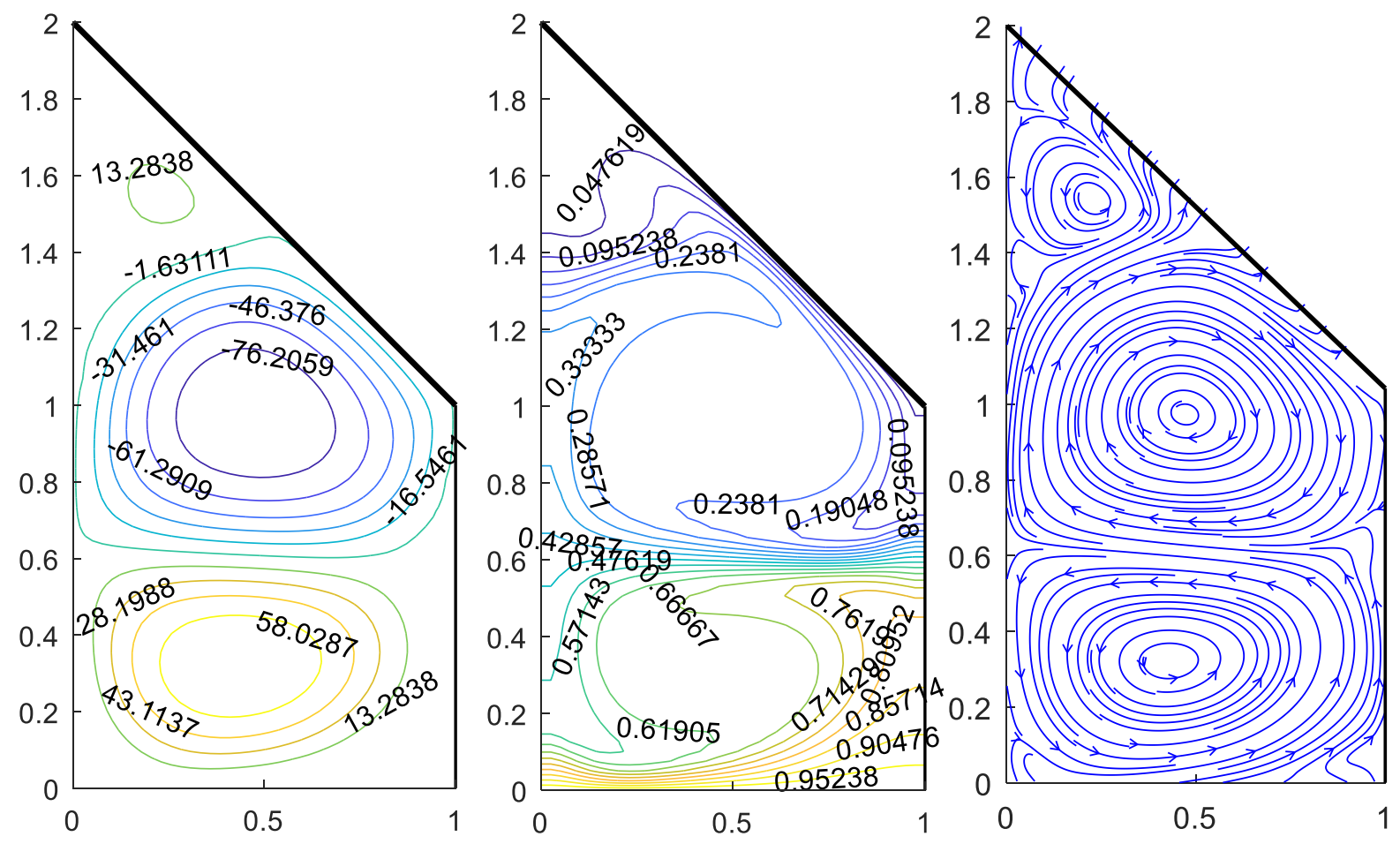

Fig. 5. Streamlines $(\psi)$, Isotherms $(\theta)$ and Energy flux Vector $(\bar{E})$ for $\operatorname{Ra}=10^{6}, \operatorname{Rd}=1, \operatorname{Pr}=0.7$
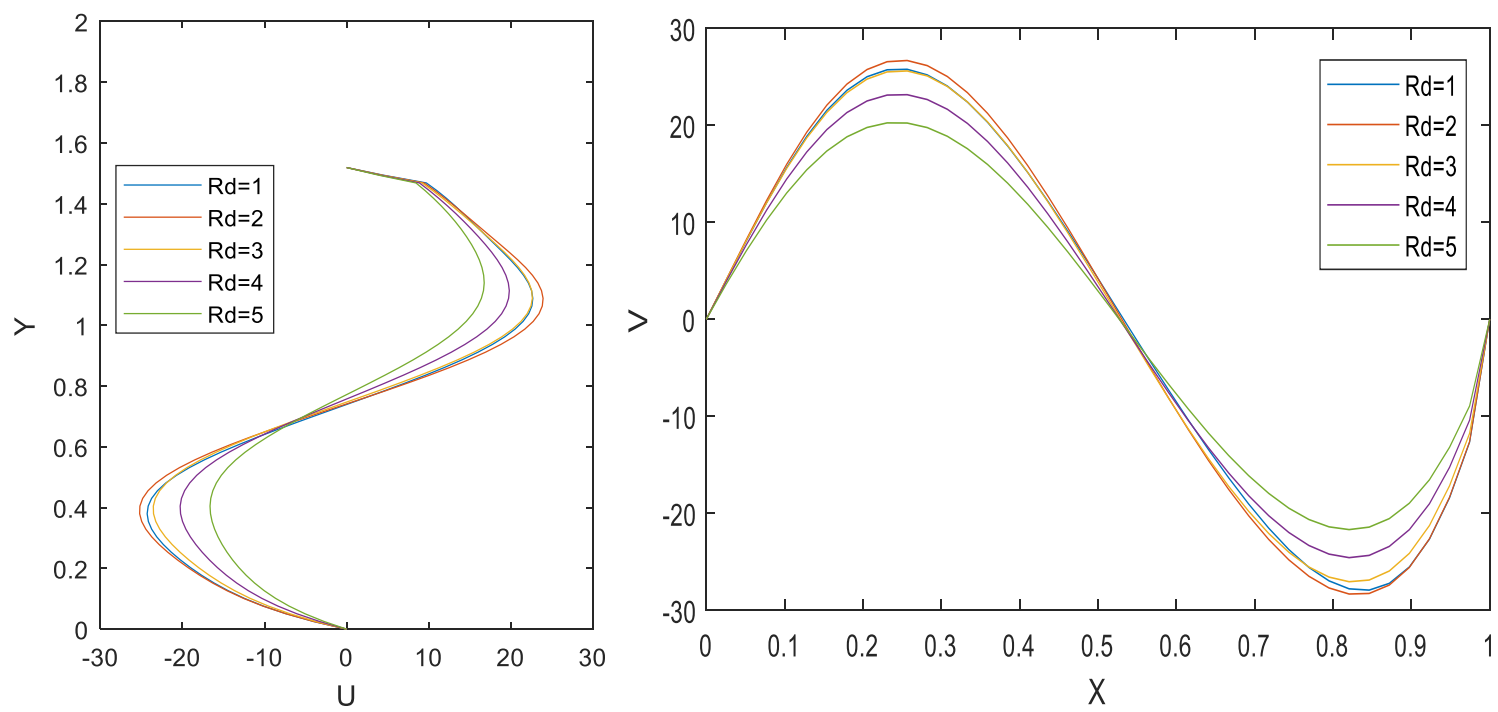

Fig. 6.Mid-section velocity profiles different values ofthermal radiation parameter for $\mathrm{Ra}=10^{4}$. 


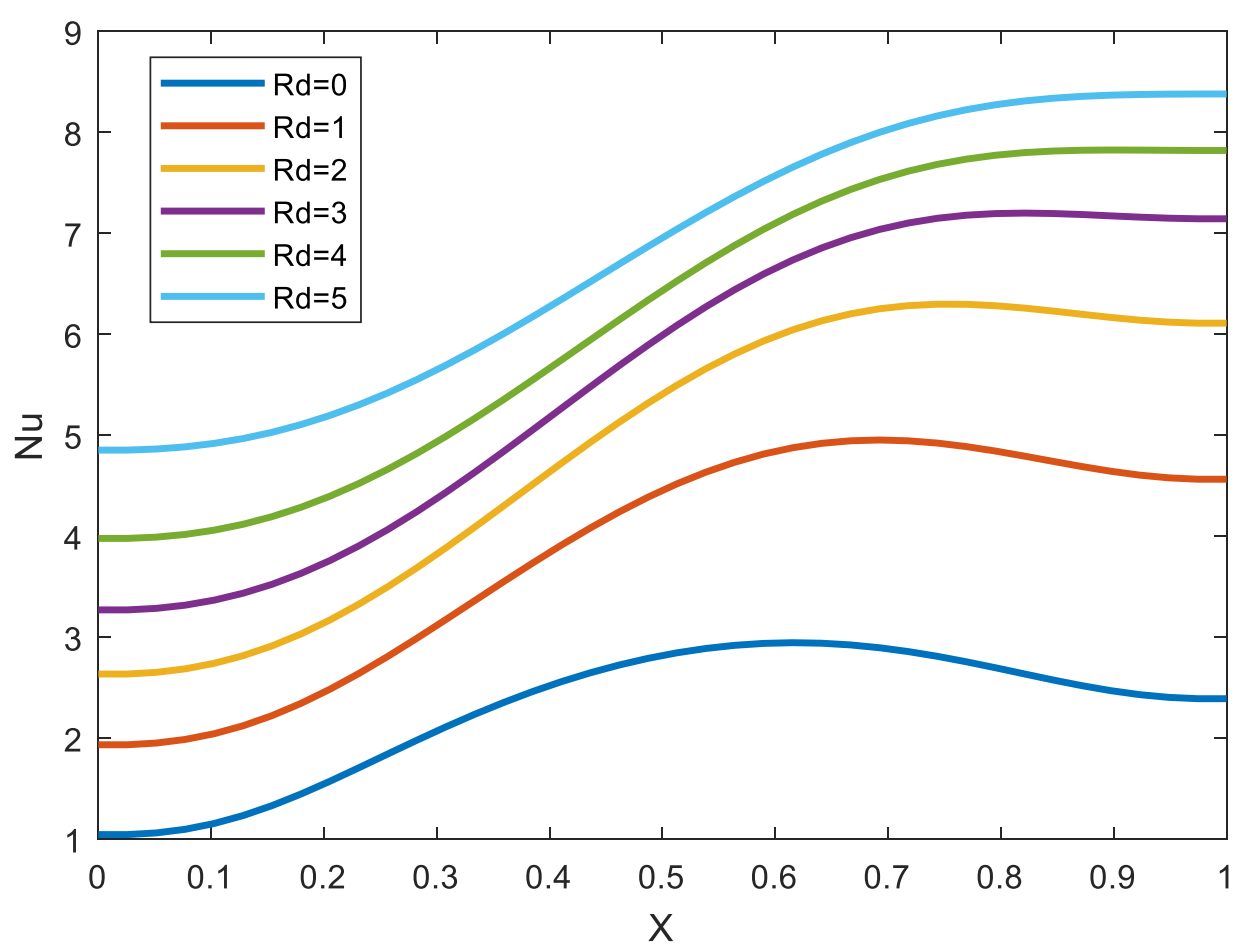

Fig. 7.Local Nusselt number at base wall for various values of $\mathrm{Rd}$ with $\mathrm{Ra}=10^{4}$.

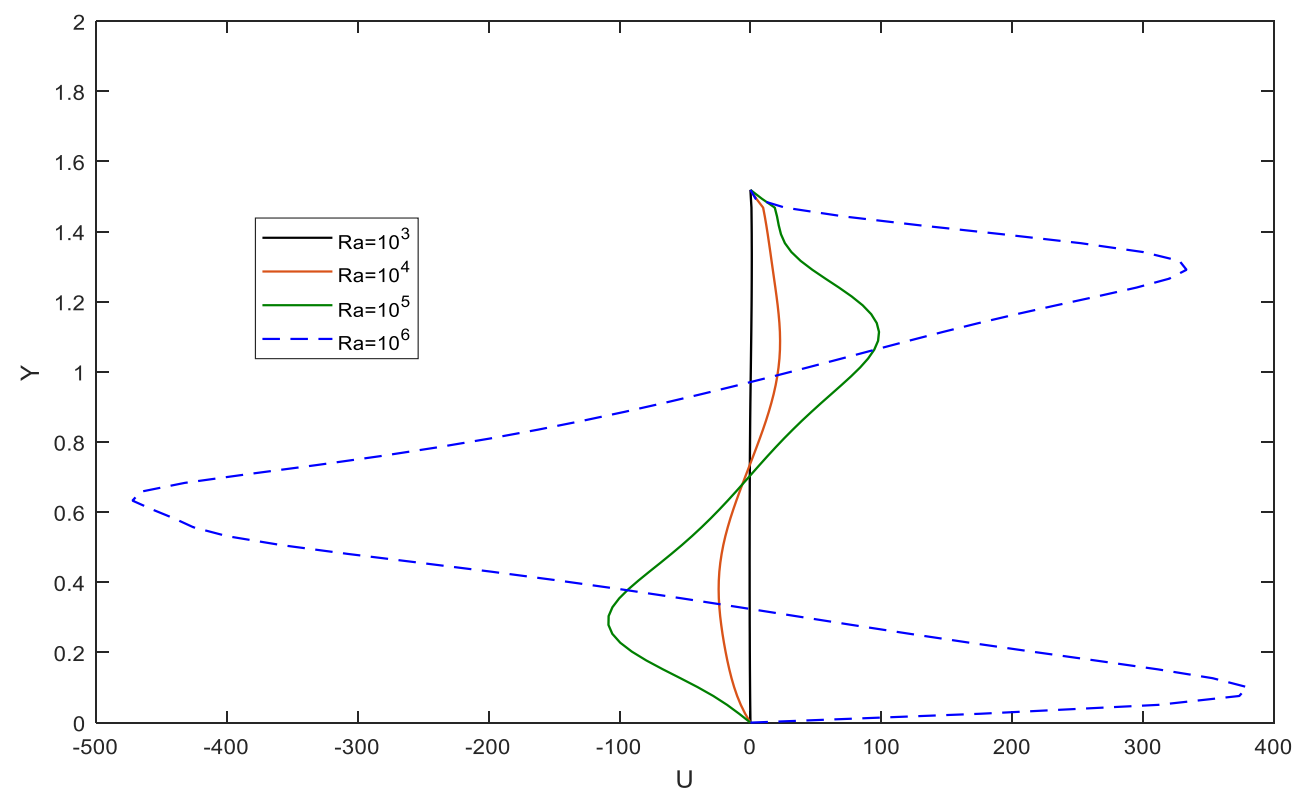

Fig. 8.Mid-section velocity profile $\mathrm{U}$ with different values of $\mathrm{Ra}$ for $\mathrm{Rd}=1$. 


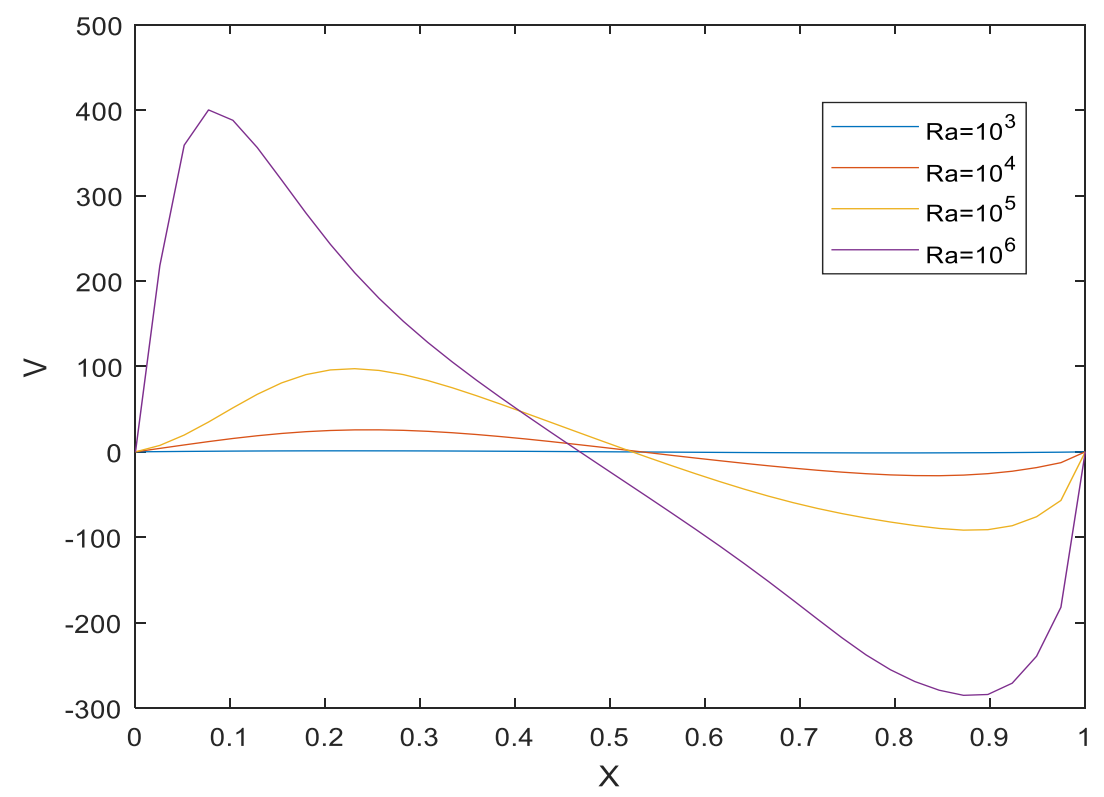

Fig. 9.Mid-section velocity profile $\mathrm{V}$ with different values of $\mathrm{Ra}$ for $\mathrm{Rd}=1$.

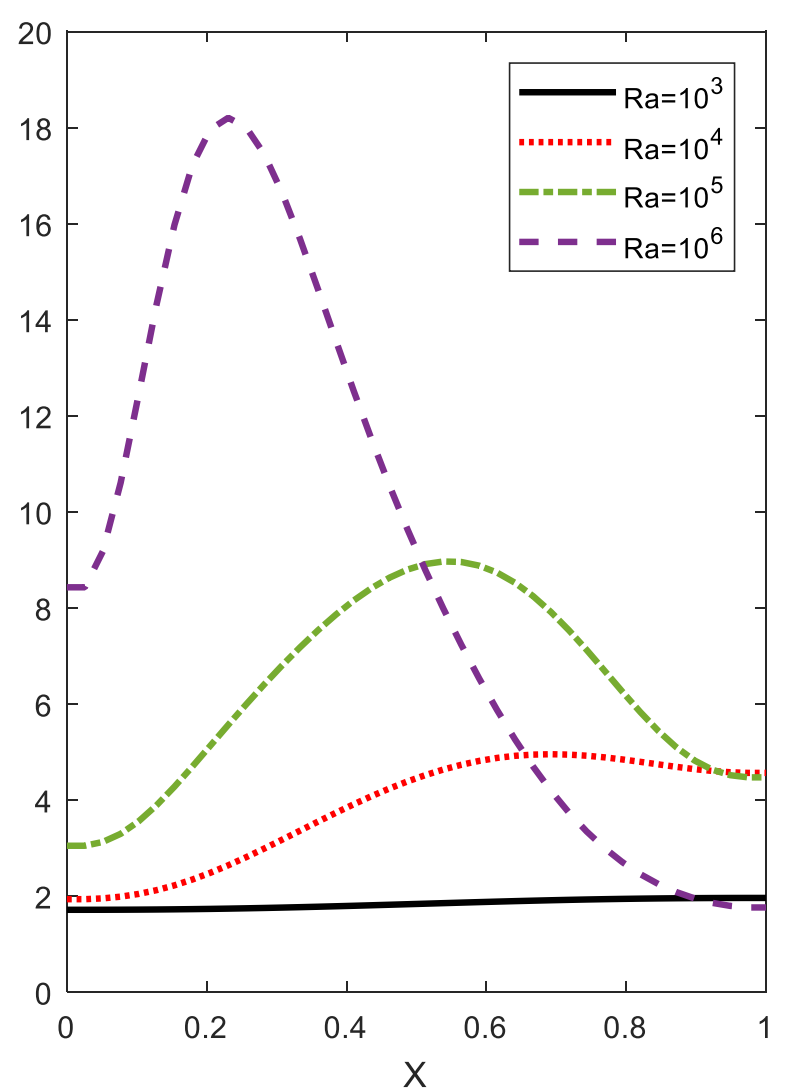

Fig. 10. Local Nusselt number along the bottom wall for different values of $\operatorname{Ra}$ for $\operatorname{Rd}=1, \operatorname{Pr}=0.7$. 